\title{
Measuring Locomotor Training Performance With Mechanical Performance and Motoric Tests in the Case of Young Soccer Players
}

\author{
Ádám Gusztafik ${ }^{1}$ and Miklós Koltai ${ }^{1}$ \\ Eötvös Loránd University (ELTE), Faculty of Education and Psychology (PPK), Institute of \\ Sport Sciences, Szombathely, Hungary \\ adam.gusztafik@gmail.com
}

Please cite as: Gusztafik, Á., \& Koltai, M. (2020). Title. Measuring Locomotor Training Performance With Mechanical Performance and Motoric Tests in the Case of Young Soccer Players. SportR $\chi i v$ https://doi.org/XX.XXXX/osf.io/XXXXX

\begin{abstract}
The monitoring of young soccer players' training load using up-to-date devices is essential from the point of view of continuous improvement at high-quality soccer academies. In the present study, we used tests that are accepted and valid in soccer, which were performed frequently to find out more about improvement. Data measured in the U15-U19 age groups at the Illés Academy in Szombathely were analyzed during the research $(\mathrm{N}=70)$. These data comprised (a) body parameters and performance trials: Body Mass, Height, Yo-Yo intermittent recovery test-level 1 (YYIR1), 30 m running, Functional Movement Screening (FMS), and Standing Long Jump (SLJ). (b) Locomotor parameters using the 6-week averages of Catapult OptimEye S5 standardized weekly reports of locomotor performance data (weeks 42-47, 2019): Total Time, Total Distance (m), Velocity Bands 4-6 Average Effort counts and distances, and Maximum Velocity. (c) Mechanical performance parameters: Total Player Load (TPL), highintensity acceleration, high-intensity deceleration, Change of Direction (CoD) Left, High, CoD Right, High, and Explosive Effort (EE). The Illés Academy players did well in the motoric tests: YYIR1 $(M=2155, S D=311), 30 \mathrm{~m}(M=4.34, S D=0.26)$, and SLJ $(M=2.28, S D=0.18)$, and the different age groups underwent dynamic improvement. The young soccer players ran $19,552 \mathrm{~m}$ on average in their weekly training sessions $(S D=4562)$ : players ran 568,298 , and $97 \mathrm{~m}$ in the moderate-, high-, and sprint-intensity zones (Velocity Band 4-5-6 Average Distance) $(S D=287,148$, and 67). The number of moderate-, high-, and sprint-intensity actions (Velocity Band 4-5-6 Average Effort Counts) was $M=58.32,24.24$, and 6.20 ( $S D=24.41$, 11.30, and 3.74). The athletes' maximum speed was $M=26.72 \mathrm{~km} / \mathrm{h}(S D=1.74)$. The differences between the age groups were justified statistically in each case. Moderate or more intensive correlations were not found between the different intensity of running and the body parameters. High-intensity correlations were found between the completed total distance and the number of moderate-intensity actions $(r=0.806, p<.001)$, and high correlations were found between the moderate-intensity and high-intensity running $(r=0.933, p<.001)$.
\end{abstract}

Keywords: young soccer players, Catapult, locomotor performance

All authors have read and approved this version of the manuscript. This article was last modified on Month 12, 2020. 


\section{INTRODUCTION}

Revolutionary changes in performance monitoring can be seen in the world of sport. Extensive measuring is no longer the privilege of sports celebrities but has become natural among elite young athletes. Several physiological and sports-specific parameters can be monitored, which provide young soccer players with optimal load scheduling and progressive improvement opportunities. Global positioning systems (GPS) offer new opportunities in different sports (Cummins et al., 2013). Anthropometric parameters have a significant impact on the motoric performance of different age groups in the case of young people (Russel \& Tooley, 2011). By the age of 18 , the reference values for height and weight in the case of professional soccer players are $177 \mathrm{~cm}$ and $70-71 \mathrm{~kg}$ (Chamari et al., 2004).

Locomotor performance is one of the key performance components in a match and is measured in relation to speed and distance. Significantly different values can be recorded for the different parameters even at a young age (Buchheit et al., 2010). Basic endurance, for which one of the parameters is Total Distance (TD), is a significant conditional factor and is between 9 and $12 \mathrm{~km}$ in a match of 90 minutes in the case of adults, according to the literature (Wehbe et al., 2014; Vigne et al., 2012; Di Salvo et al., 2007). The distances differ with respect to movement and intensity in the case of the different playing positions (Rienzi et al., 2000; Rampinini et al., 2007), which require a wide range of intensity, from low to maximum, during a match (Orendurff et al., 2010), depending on the game strategy (Tierney et al., 2016). There is a significant difference in terms of completed distance in the two halves of the match: It is between $1 \%$ and $8 \%$ longer in the first half in the case of professional soccer players (Di Salvo et al., 2007; Rampinini et al., 2007). A continuous improvement in performance with respect to each parameter can be found with age in the case of young soccer players (U13-U18) (MendezVillanueva et al., 2012). The $19.8 \mathrm{~km} / \mathrm{h}$ and $21 \mathrm{~km} / \mathrm{h}$ thresholds on the locomotor scale are a significant performance parameter. This is referred to as high-intensity running in the technical literature (Krustrup et al., 2003) and makes up 3\% of a match (Di Mascio \& Bradley, 2013).

The most intensive period in a match can provide valuable information for the scheduling of endurance training sessions. Data from this period can be used in the case of each parameter. Bradley and his colleagues (2009) analyzed the high-intensity period - a period of 5 minutesin Premier League matches. The completed distance was $231 \mathrm{~m}$ on average. In the following 5 minutes, players could run only $131 \mathrm{~m}$ in this zone. This highlights the significance of exhaustion and endurance and the periodicity that is specific to these games (Mallo, 2014). High-intensity running is followed by sprinting, when players run distances at $25.2 \mathrm{~km} / \mathrm{h}$. Di Salvo and his colleges (2010) analyzed Champions League and UEFA Cup matches from 2002 to 2006. They monitored a total of 717 players from 58 teams from 20 countries. According to their findings, the sprint counts were between 17 and 35. Defenders performed least well, while wide midfielders did best. Most of the distances were run in the sprint zone, in the $0-5 \mathrm{~m}$ and 5-10 m ranges. Barnes and his colleagues (2014) claimed that average sprint counts rose to 57 and average sprint distances to $5.9 \mathrm{~m}$ when monitoring Premier League matches. The basis for meeting such requirements is adaptation in relation to repeated-sprint ability (RSA) (Bishop et al., 2011). This ability was first described as a significant factor in performance in ballgames in the early 2000s. Fernandes-Da-Silva and his colleagues (2019) had young soccer players perform $5 \times 30 \mathrm{~m}$ sprints with breaks of 30 seconds. The findings of the test were compared with sprint performance in matches. The authors found a strong correlation $(r=0.6)$ between the sprint test results and the sprint counts in matches. Selmi and his colleagues (2018) published an article on the complexity of RSA in the case of young soccer players.

Bangsbo and his colleagues (2008) developed a standard test for assessing endurance in soccer. The test comprises periods of progressively increasing intensity. According to the authors, a distance of 2,200 $\mathrm{m}$ is average at the age of 17-18, depending on the player's position. Ružbarský and his colleagues (2017) recorded similar findings among Slovakian elite U17

All authors have read and approved this version of the manuscript. This article was last modified on Month 12, 2020. 
soccer players. Boullosa and his colleagues (2013) devised an 8-week coaching program for Spanish elite soccer players. By planning and monitoring the detailed load factors, average pulse values decreased from $191.2 \pm 6.8$ to $179.0 \pm 7.5$ while performing YYIR1. Adaptation processes showed similar good values according to regeneration samples after small-sided games (SSG), as 3 seconds after stopping the load there were significant discrepancies. Bravo and his colleagues (2008) analyzed the sprint test (or RSA) and the impact of high-intensity interval training (HIIT) on soccer players for 7 weeks by performing several tests. Players doing repeated-sprint training did $28 \%$ better, while players doing HIIT did $12.5 \%$ better in terms of the distances run in meters during a YYIR1. However, the authors emphasized that the two methods should be used in combination to ensure successful adaptation. Helgerud and his colleagues (2007) analyzed the impact of different endurance-improving methods on university students three times a week for 8 weeks. They found that HIIT resulted in better oxygen intake than continuous methods.

We had previously carried out several measurements to test performance and endurance: (a) the correlations between technique and reaction time combined with choice (Koltai et al., 2016); and (b) the impact of body composition and endurance on agility in motoric tests (Gusztafik et al., 2019). We consider these to be the key parameters, complemented by the GPS monitoring of training sessions and matches, for assessing soccer players' efficiency.

Tactical periodization and internal and external load need to be planned simultaneously (Verheijen, 2014). FMS is a testing method that includes seven exercises to assess and predict players' movement patterns, body asymmetry, and injury risk (Cook, 2011). Marques and his colleagues (2017) undertook measurements among Brazilian U14-U20 soccer players. They found asymmetry in $65 \%$ of the players in five out of the seven tests involving unilateral exercises.

\section{METHODS}

The present study involved U15, U16, U17, and U19 soccer players at the Illés Academy in Szombathely. We recorded data for 70 players in the sample. The study was approved by the ELTE Research Ethics Committee (approval number 2020/20). The tests used for the measurements were tests that are used by the academy, thus they were not new to the players. We collected three different kinds of data. We used InBody 770 (https://inbody.com/global/intro/Technology.aspx) to record the players' body parameters: Body Mass (kg), Height (cm), Skeletal Muscle Mass (SMM), Body Fat percentage (BFP), and Body Mass Index (BMI). We then carried out motoric tests. Prior to the tests, we informed the players about the testing process and they had done a 15-minute warm-up session. We used YYIR1 (Bangsbo et al., 2008), which is specific to soccer players, to assess the players' endurance. The players' linear speed was tested using the OXA Starter+ infrared timing gate system, and they had to run $30 \mathrm{~m}$. They had two attempts, just as when measuring speed force using SLJ, and we recorded the better results only. To analyze movement patterns we used FMS (Cook, 2011). We used the Catapult OptimEye S5 (https://www.catapultsports.com/products/optimeye-s5) sensor to analyze the weekly average standardized locomotor performance of the weeks 42-47 microcycle in 2019, which was week 14 according to the competition periodicity of the academy. We chose this period due to the high-intensity training targets during these weeks, which we aimed to verify by means of statistical analysis. We used the following values: TD (m), Total Time, Velocity Band 4 Average Effort Count and Distance (14.4-19.8 km/h), Velocity Band 5 Average Effort Count and Distance (19.8-25.2 km/h), Velocity Band 6 Average Effort Count and Distance (> 25.2 $\mathrm{km} / \mathrm{h}$ ), and Maximum Velocity.

All authors have read and approved this version of the manuscript. This article was last modified on Month 12, 2020. 
To facilitate comparison, we used some Mechanical performance values that are characterized by noncyclic movements: Total Player Load (TPL); high-intensity Acceleration; high-intensity Deceleration; CoD Left, High; CoD Right, High; and Explosive Effort (EE).

We processed the data using IBM SPSS Statistics $25(p<.05)$. We carried out linear regression analysis, one-way analysis of variance (ANOVA), and correlation matrix analysis, besides descriptive statistics.

\section{RESULTS}

The BFP values turned out not to follow the normal distribution. Their skewness and kurtosis values were high, and the quotients of these values and their standard errors were also high. The ANOVA F-test was not significant because of the U17 team's extremely low BFP. The average of the other values showed discrepancies according to the different age groups and could thus be compared. The average body mass was $64.79 \mathrm{~kg}$, with an average SMM of 33.44 $\mathrm{kg}$ at the Illés Academy. The average Body Fat Mass (BFM) value of $8.1 \%$ and average BMI of 20.61 were normal. Body mass showed a strong correlation with all three values. Body mass showed a moderate correlation with the $30 \mathrm{~m}$ speed test and SLJ test. At the same time, Skeletal Muscle Mass showed a strong correlation with running speed and SLJ. According to the conclusions drawn on the basis of the tests, the performance tests, endurance test, and speed and SLJ tests also showed correlations (Table 1).

\section{Analysis of the Locomotor Factors}

The values consisted of the weekly averages for the 6-week period. The TD values in meters showed a high distribution across the whole sample $(M=19552 ; S D=4562)$. The moderate-intensity Velocity Band 4 Average Distance (VB4ADI; 14.4-19.8 km/h) for running was $M=568.298(\mathrm{SD}=287)$, and the moderate-intensity Velocity Band 4 Average Effort Count (VB4AEC) was $M=5832(S D=2424)$. The respective values in the case of Velocity Band 5 $(19.8-25.2 \mathrm{~km} / \mathrm{h})$ were $M=306.14(S D=143.98)$ and $M=24.79(S D=10.95)$, and in the case of velocity band 6 (speed $>25.2 \mathrm{~km} / \mathrm{h})$ they were $M=99.30(S D=66.27)$ and $\mathrm{M}=6.14(S D=$ 3.77).

Maximum velocity refers to the Maximum Speed delivered at training sessions $(M=$ 26.66; $S D=1.72$ ).

The outstanding maximum performance in the locomotor tests was TD $=28,135$, VB5ADI = 667; VB6ADI = 249; and MV = 29 (Table 2).

\section{Tests of Normality}

We used the Kolmogorov-Smirnov and Shapiro-Wilk tests to measure characteristic parameters for locomotor performance. The latter test yielded results that were more similar to our sample. We recorded significant results $(p<.05)$ with the exception of TD and VB4AEC $(14.4-19.8 \mathrm{~km} / \mathrm{h})$. The quotient of the skewness values and the standard error values was not higher than \pm 2.58 , and the respective value was \pm 1.96 in the case of the kurtosis values. The boxplot graphs showed normal distribution. The very different values were not taken into consideration in further analyses (Table 3 ).

\section{Averages for the Different Age Groups}

Using the one-way ANOVA, we observed that, with the exception of the VB6AEC (> $25.2 \mathrm{~km} / \mathrm{h}$ ), all locomotor values were significant in the F-tests, depending on the age group. This is why, with the exception of the VB6AEC, the averages for the different age groups showed significant discrepancies and the results could be compared.

In the case of the different teams belonging to the different age groups, there was a uniform increase in the Velocity Band 4-5 Distance. At the same time, we observed a significant

All authors have read and approved this version of the manuscript. This article was last modified on Month 12, 2020. 
decrease in the Velocity Band 4-5 count in the U19 players. We therefore suppose that the players delivered a lower number of distances, although the distances were longer, in the same period of time. It is worth mentioning that the U19 players ran the shortest mean TD in their training sessions (Figure 1).

The U16 players' lower average performance in the case of VB6ADI (> $25.2 \mathrm{~km} / \mathrm{h}$ ) was also noticeable, while the team's average velocity showed an increase.

\section{Relationships Between the Different Values}

We observed the following relationships between the locomotor performance values: the values for VB6AEC and Max. Velocity showed a high correlation $(r=0.776 ; p<.001)$. However, the other values did not show any correlation, or showed a low correlation.

The measured Total Distances and the action counts were high in the same time periods, and we can presume a significant relationship between them. The only exception was VB6AEC, where the values did not follow the normal distribution. This indicates a significant or moderate relationship between TD and VB4AEC $(r=0.776 ; p<.001)$ and the other values for the other time periods.

The high correlation between the different speed zones showed that the players were able to deliver similar performance levels in the different time zones.

We reached these conclusions on the basis of the body parameter performance tests and the relationships of the locomotor load variables. The distances in the different speed zones and the different intensity zone counts showed a significant to moderate relationship $(r=0.301-$ $0.476, p<.001$ and $p=.305-.566)$ with the $30 \mathrm{~m}$ running and SLJ. Max. Velocity showed weaker than moderate and significant correlations with body parameters $(p=.296-.339 ; p<$ .05) (Table 4).

At the same time, the YYIR1 values did not show any correlation with the locomotor parameters. We introduced new variables due to the lack of correlations: We compared the > $14.4 \mathrm{~km} / \mathrm{h}$ Velocity Bands Counts in different speed zones (4-5-6) so that we could analyze the lack of correlations more carefully. We then introduced the $>19.8 \mathrm{~km} / \mathrm{h}$ speed zone counts. We concluded that the internationally standardized YYIR1 test to measure a player's velocity endurance is completely independent from locomotor tests measuring the different speed zone distances and counts in the analyzed sample (Table 5).

We then analyzed the relationship between the locomotor endurance and mechanical endurance variables measured during the training sessions. The strong correlation between TD and TPL $(r=0.881, p<.001)$ indicated the calculation accuracy of the software. TD showed a strong correlation with the high-intensity Deceleration, CoD Left, High, and EE values ( $r=$ 0.637, 0.485, 0.436; $p<.001)$. It had no correlation with the Velocity Band Count High values (Table 6).

There was a moderate correlation between the variables in the different speed zones and the mechanical load values. Max. Velocity showed a low correlation with the Velocity Band Count High variables but was independent of the other mechanical load variables.

\section{Scatter/Dot Diagrams}

Coaches are provided with extra information on the basis of the players' performance in tasks that require different skills. These tasks can show how versatile the players are. In Figures 2, 3, and 4, the y axis indicates the YYIR1 values. Each dot in the scatter/dot diagrams symbolizes a player. The $\mathrm{x}$ axis shows the maximum velocity, VB6ADI, and total distance values. Players whose dots are farthest from the pole and whose $\mathrm{x}$ and $\mathrm{y}$ axis values are the highest delivered the best performance. The three scatter/dot diagrams show the performance of the different age groups and teams, and their values can be compared (Figure 2, Figure 3, Figure 4).

All authors have read and approved this version of the manuscript. This article was last modified on Month 12, 2020. 


\section{CONCLUSIONS}

We analyzed the locomotor performance of young (U15-U19) soccer players over 6 weeks during training sessions, as well as the relationship between locomotor performance and the mechanical load and motoric tests. The analytical examination of body parameters and physical test results took place according to international practice (Sylejmani et al., 2019). The movement and motoric tests showed the key parameters of the players' performance during matches (Rampinini et al., 2007). The values showed discrepancies in terms of quality (Velocity Bands 5-6) and quantity (TD) according to the different age groups, which can be explained in different ways despite the correlations with respect to the speed zones. The soccer-specific YYIR1 endurance test showed regular improvement in the case of the different age groups, similarly to the international analytical test results of Bangsbo et al. (2008) and the test results of Ružbarský et al. (2017) involving Slovakian elite U17 soccer players. One possible explanation could be the different skill levels of the different age groups (Tierney et al., 2016), while the different management styles and attitudes to the game on the part of the coaches who work with the different age groups might influence the performance and training session variables. We found correlations between the values for locomotor and mechanical load, which emphasizes the significance of periodicity (Verheijen, 2014). This should be complemented with cardiovascular monitoring, covering the players' match and training session load factors (Boullosa et al., 2013). A moderate correlation was observed in the case of the total player load test results in the U19 age group, and in the U17 age group's FMS test results. In the case of the former age group, the main reason for the decreasing average test results is the fact that the youngsters in this age group are almost adult soccer players, and quality indicators are the main target. This is why U19 soccer players have a shorter but more intensive workload. It is still early days for the standardization of these variables, especially in the case of young soccer players. The FMS prevention factor and regular monitoring are key to the efficiency of the movement samples (Cook, 2011). The decreasing FMS test results in the case of the U17 age group are due to the lower test results recorded by players joining the team in the summer, whose movement patterns need improvement. As movement patterns were unimportant at their previous clubs, the new players need to catch up with their more established teammates. The results of the FMS tests correlate with the Brazilian data recorded by Marques et al. (2017). Feedback about the different age groups, and the measured similarities and discrepancies in the case of the different age groups and their causes, are important for head coaches and the experts who run academies. The dynamic improvement in Jump Count Band High test results is due to the gradual increase in physical strength, which is age group specific, and the high expectations with respect to players' performance. It is worth bearing in mind the connection between EE and high-intensity Acceleration and Deceleration, which both require extreme eccentric muscle performance (Harper et al., 2019).

In the present study, we analyzed the data for U15-U19 soccer players. It is important to analyze periodicity, load, and the differentiation of the various training parameters in the case of the different age groups in order to ensure permanent development and improvement. Modern GPS performance monitoring provides an opportunity for real-time monitoring, which makes it possible to introduce load compensation at the end of a training session if necessary, so that the load becomes equal within the team. Such processes, and the standardization of the load values, are becoming more and more up to date in soccer in Hungary.

\section{CONTRIBUTIONS}

Authors should report the contributions of each author in the a specific contribution section based on the guidelines set forth by the International Committee of Medical Journal Editors. Please indicate author contributions as clearly as possible, according to the following criteria:

Substantial contributions to conception and design

All authors have read and approved this version of the manuscript. This article was last modified on Month 12, 2020. 
Acquisition of data

Analysis and interpretation of data

Drafting the article or revising it critically for important intellectual content

Final approval of the version to be published

Example:

DOI: STORK.3389.XXXX

\section{REFERENCES}

[1] Bangsbo, J., Iaia, M., \& Krustrup, P. (2008). The Yo-Yo Intermittent Recovery Test. A useful tool for evaluation of physical performance in intermittent sports. Sports Medicine, 38(1), 37-51.

[2] Barnes, C., Archer, D. T., Hogg, B., Bush, M., \& Bradley, P. S. (2014). The Evolution of Physical and Technical Performance Parameters in the English Premier League. International Journal of Sports Medicine, 35(13), 1095-1100.

[3] Bishop, B. J., Girard, O., \& Mendez-Villanueva, A. (2011). Repeated-Sprint Ability Part II: Recommendations for Training. Sports Medicine, 41(9), 741-756.

[4] Boullosa, D. A., Abreu, L., Nakamura, F. Y., Munoz, V. E., Domínguez, E., \& Leicht, A. S. (2013). Cardiac Autonomic Adaptations in Elite Spanish Soccer Players During Preseason. International Journal of Sports Physiology and Performance, 8, 400-409.

[5] Bradley, P. S., Sheldon, W., Wooster, B., Olsen, P., Boanas, P., \& Krustrup, P. (2009). High-Intensity Running in English FA Premier League Soccer Matches. Journal of Sports Sciences, 27(2), 159-168.

[6] Bravo, F. D., Impellizzeri, F. M., Rampinini, E., Castagna, C., Bishop, D., \& Wisloff, U. (2008). Sprint vs. Interval Training in Football. International Journal of Sports Medicine, 29, 668-674.

[7] Buchheit, M., Mendez-Villanueva, A., Simpson, B. M., \& Bourdon, P. C. (2010). Match Running Performance and Fitness in Youth Soccer. International Journal of Sports Medicine, 31, 818-825.

[8] Chamari, K., Hachana, Y., Ahmed, Y. B., Galy, O., Sghaier, F., Chatard, J. C., Hue, O., \& Wisloff, U. (2004). Field and laboratory testing in young elite soccer players. British Journal of Sports Medicine, 38, 191-196.

[9] Cook, G. (2011). Movement: Functional Movement Systems: Screening, Assessment, Corrective Strategies. Lotus Pub.

[10] Cummins, C., Orr, R., O’Connor, H., \& West, C. (2013). Global Positioning Systems (GPS) and Microtechnology Sensors in Team Sports: A Systematic Review. Sports Medicine, 43(10),1025-1042.

[11] Di Mascio, M., \& Bradley, P. S. (2013). Evaluation of the most intense highintensity running period in English FA premier league soccer matches. Journal of Strength and Conditioning Research, 27(4), 909-915.

All authors have read and approved this version of the manuscript. This article was last modified on Month 12, 2020. 
[12] Di Salvo, V., Baron, R., González-Haro, C., Gormasz, C., Pigozzi, F., \& Bachi, N. (2010). Sprinting Analysis of Elite Soccer Players During European Champions League and UEFA Cup Matches. Journal of Sports Sciences, 28(14), 1-6.

[13] Di Salvo, V., Baron, R., Tschan, H., Calderon Montero, F. J., Bachl, N., \& Pigozzi, F. (2007). Performance Characteristics According to Playing Position in Elite Soccer. International Journal of Sports Medicine, 28, 222-227.

[14] Fernandes-Da-Silva, J., Castagna, C., \& Teixeira. A.S. (2019). Ecological and Construct Validity of a Repeated Sprint Test in Male Youth Soccer Players. Journal of Strength and Conditioning Research (January), 1-10.

[15] Gusztafik, Á., Halasi, Sz., Lepeš J., Nagyváradi, K., Szeiler, B., \& Koltai, M. (2019). The connections between agility, endurance and motor skill tests in Serbian junior soccer players. Tanulmánygyüjtemény. University of Novi Sad Hungarian Language Teacher Training Faculty, 10-23.

[16] Harper, D. J., Carling, C., \& Kiely, J. (2019). High-Intensity Acceleration and Deceleration Demands in Elite Team Sports Competitive Match Play: A Systematic Review and Meta-Analysis of Observational Studies. Sports Medicine 49,1923-1947.

[17] Helgerud, J., Høydal, K., Wang, E., Karlsen, T., Berg, P., Bjerkaas, M., Simonsen, T., Helgesen, C., Hjorth, N., Bach, R., \& Hoff, J. (2007). Aerobic HighIntensity Intervals Improve VO2max More Than Moderate Training. Medicine and Science in Sports and Exercise 39(4), 665-671.

[18] Koltai, M., Wallner, D., Gusztafik, Á., Sáfár, Z., Dancs, H., Simi, H., Hagenauer, M., \& Buchgraber, A. M.(2016). Measuring of sport specific skills of football players. Journal of Human Sport and Exercise 11(1), 218-227.

[19] Krustrup, P., Mohr, M., Amstrup, T., Rysgaard, T., Johansen, J., Steensberg, A., Pedersen, P. K., \& Bangsbo, J. (2003). The Yo-Yo Intermittent Recovery Test: Physiological Response, Reliability, and Validity. Medicine and Science in Sports and Exercise, 35(4), 697-705.

[20] Mallo, J. (2014). Periodization Fitness Training. SoccerTutor.

[21] Marques, V. B., Medeiros, T. M., Stigger, F. S., \& Nakamura, F. Y. (2017). The Functional Movement Screen (FMS TM) in Elite Young Soccer Players Between 14 and 20 Years: Composite Score, Individual-Test Scores and Asymmetries.

International Journal of Sports Physical Therapy 12(6), 977-985.

[22] Mendez-Villanueva, A., Buchheit, M., Simpson, B., \& Bourdon, P. C. (2012). Match Play Intensity Distribution in Youth Soccer. International Journal of Sports Medicine 34, 101-110.

[23] Orendurff, M. S., Walker, J. D., Jovanovic, M., Tulchin, K. L., Levy, M., \& Hoffmann, D. K. (2010). Intensity and duration of intermittent exercise and recovery during a soccer match. Journal of Strength and Conditioning Research, 24(10), 26832692 .

All authors have read and approved this version of the manuscript. This article was last modified on Month 12, 2020. 
[24] Rampinini E., Coutts A. J., Castagna, C., Sassi, R., \& Impellizzeri, F. M. (2007). Variation in Top Level Soccer Match Performance. International Journal of Sports Medicine, 28(12), 1018-1024.

[25] Rienzi, E., Drust, B., Reilly, T., Carter, J. E., \& Martin, A. (2000). Investigation of anthropometric and work-rate profiles of elite South American international soccer players. Journal of Sports Medicine and Physical Fitness, $40(2), 162-169$.

[26] Russel, M., \& Tooley, E. (2011). Anthropometric and Performance Characteristics of Young Male Soccer Players Competing in the UK. Serbian Journal of Sports Sciences, 5, 155-162.

[27] Ružbarský, P., Vadašová, B., Eliaš, T., Čech, P., \& Jančošek, M. (2017). Aerobic Fitness of 17-Year-Old Soccer Players Throughout the Annual Training Cycle According to Their Playing Position. Scientific Journal of Education, Sports, and Health, 18(2), 156-164.

[28] Selmi, M. A., Sassi, R. H., Yahmed, M. H., Giannini, S., Perroni, F., \& Elloumi, M. (2018). Normative Data and Physical Determinants of Multiple Sprint Sets in Young Soccer Players Aged 11-18 Years: Effect of Maturity Status. Journal of Strength and Conditioning Research, 34(2), 506-512.

[29] Sylejmani, B., Maliqi, A., Gontarev, S., Haziri, S., Morina, B., Durmishaj, E., \& Bajrami, A. (2019). Anthropometric Characteristics and Physical Performance of Young Elite Kosovo Soccer Players. International Journal of Morphology, 37(4), 1429-1436.

[30] Tierney, P. J., Young, A., Clarke, N. D., \& Duncan, M. J. (2016). Match play demands of 11 versus 11 professional football using Global Positioning System tracking: Variations across common playing formations. Human Movement Science, $49,1-8$.

[31] Verheijen, R. (2014). The Original Guide to Football Periodisation Part I. World Football Academy.

[32] Vigne, G., Dellal, A., Gaudino, C., Chamari, K., Rogowski, I., Alloatti, G., Wong, D. P., Owen, A., \& Hautier, C. (2012). Physical Outcome in a Successful Italian Serie A Football Team over 3 Consecutive Seasons. Journal of Strength and Conditioning Research, 27(5), 1400-1406.

[33] Wehbe, G., Hartwig, T., \& Duncan, C. (2014). Movement Analysis of Australian National League Soccer Players Using Global Positioning System Technology. Journal of Strength and Conditioning Research, 28(3), 834-842.

[34] InBody770 (https://inbody.com/global/intro/Technology.aspx)

[35] Catapult OptimEye S5 (https://www.catapultsports.com/products/optimeye-s5)

All authors have read and approved this version of the manuscript. This article was last modified on Month 12, 2020. 


\section{Table 1}

Correlation Between Body Parameters and Performance Trials

\begin{tabular}{|c|c|c|c|c|c|c|c|c|}
\hline & & & Corr & tions & & & & \\
\hline & & & Skeletal & Body & & & & \\
\hline & & & Muscle & Mass & Yo-Yo & & & Long \\
\hline & Weight & Height & Mass & Index & IRTL1 & $30 \mathrm{~m}$ & FMS & Jump \\
\hline Weight & 1 & $.781^{\star *}$ & $.953^{\star *}$ & $.821^{* \star}$ & 0.107 & $-.522^{\star \star}$ & -0.052 & $.551^{* \star}$ \\
\hline Height & $.781^{\star \star}$ & 1 & $.824^{\star *}$ & $.445^{\star *}$ & $.293^{*}$ & $-.492^{* *}$ & -0.015 & $.626^{\star *}$ \\
\hline Skeletal Muscle & $.953^{* *}$ & $.824^{* *}$ & 1 & $.768^{* *}$ & 0.174 & $-.602^{* *}$ & -0.059 & $.635^{* *}$ \\
\hline Mass & & & & & & & & \\
\hline Body Mass Index & $.821^{* *}$ & $.445^{* *}$ & $.768^{* *}$ & 1 & -0.048 & $-.439^{* *}$ & -0.019 & $.407^{* *}$ \\
\hline Yo-Yo IRTL1 & 0.107 & $.293^{*}$ & 0.174 & -0.048 & 1 & $-.339^{* *}$ & $.321^{*}$ & $.370^{* *}$ \\
\hline $30 \mathrm{~m}$ & $-.522^{* *}$ & $-.492^{* *}$ & $-.602^{* *}$ & $-.439^{* *}$ & $-.339^{* *}$ & 1 & 0.136 & $-.691^{* *}$ \\
\hline FMS & -0.052 & -0.015 & -0.059 & -0.019 & $.321^{*}$ & 0.136 & 1 & 0.024 \\
\hline Long Jump & $.551^{* *}$ & $.626^{* *}$ & $.635^{* *}$ & $.407^{* *}$ & $.370^{* *}$ & $-.691^{* *}$ & 0.024 & 1 \\
\hline
\end{tabular}

Note.

** Correlation is significant at the 0.01 level (2-tailed).

${ }^{*}$ Correlation is significant at the 0.05 level (2-tailed).

\section{Table 2}

Descriptive Statistics of Locomotor Values

Descriptive Statistics

\begin{tabular}{lrrrrr} 
& N & Minimum & Maximum & Mean & $\begin{array}{c}\text { Std. } \\
\text { Deviation }\end{array}$ \\
\hline Total Distance & 70 & 7241 & 28135 & 19552.27 & 4562.80 \\
Velocity Band 4 ADI & 70 & 18 & 1292 & 580.84 & 280.09 \\
Velocity Band 4 AEC & 70 & 2 & 138 & 59.51 & 23.56 \\
Velocity Band 5 ADI & 70 & 3 & 667 & 306.14 & 143.98
\end{tabular}

All authors have read and approved this version of the manuscript. This article was last modified on Month 12, 2020. 


$\begin{array}{lrrrrr}\text { Velocity Band 5 AEC } & 70 & 0 & 62 & 24.79 & 10.95 \\ \text { Velocity Band 6 ADI } & 70 & 0 & 249 & 99.30 & 66.26 \\ \text { Velocity Band 6 AEC } & 70 & 0 & 18 & 6.14 & 3.77 \\ \text { Max. Velocity } & 70 & 21 & 29 & 26.66 & 1.72 \\ \text { Valid N (listwise) } & 70 & & & & \end{array}$

\section{Table 3}

Tests of Normality

\begin{tabular}{lcccccc} 
& \multicolumn{2}{c}{ Kolmogorov-Smirnov } & & \multicolumn{3}{c}{ Shapiro-Wilk } \\
& Statistic & df & Sig. & Statistic & df & Sig. \\
\hline Total Distance & 0.063 & 67 & $.200^{*}$ & 0.983 & 67 & 0.489 \\
Velocity Band 4 ADI & 0.090 & 67 & $.200^{*}$ & 0.954 & 67 & 0.015 \\
Velocity Band 4 AEC & 0.059 & 67 & $.200^{*}$ & 0.970 & 67 & 0.102 \\
Velocity Band 5 ADI & 0.122 & 67 & 0.015 & 0.932 & 67 & 0.001 \\
Velocity Band 5 AEC & 0.068 & 67 & $.200^{*}$ & 0.957 & 67 & 0.021 \\
Velocity Band 6 ADI & 0.123 & 67 & 0.013 & 0.933 & 67 & 0.001 \\
Velocity Band 6 AEC & 0.189 & 67 & 0.000 & 0.947 & 67 & 0.007 \\
Max. Velocity & 0.150 & 67 & 0.001 & 0.937 & 67 & 0.002
\end{tabular}

\section{Table 4}

Correlations Between the Body and Locomotor Parameters

All authors have read and approved this version of the manuscript. This article was last modified on Month 12, 2020. 


\section{Correlations}

\begin{tabular}{|c|c|c|c|c|c|c|c|c|}
\hline & & Velocity & Velocity & Velocity & Velocity & Velocity & Velocity & \multirow{3}{*}{$\begin{array}{c}\text { Max. } \\
\text { Velocity }\end{array}$} \\
\hline & Total & Band 4 & Band 4 & Band 5 & Band 5 & Band 6 & Band 6 & \\
\hline & Distance & ADI & AEC & ADI & AEC & ADI & AEC & \\
\hline Weight & 0.012 & $.337^{* *}$ & 0.096 & $.261^{*}$ & 0.177 & $.258^{*}$ & 0.163 & $.332^{* *}$ \\
\hline $\begin{array}{l}\text { Skeletal } \\
\text { Muscle Mass }\end{array}$ & 0.049 & $.354^{* *}$ & 0.162 & $.306^{*}$ & $.246^{*}$ & $.334^{* \star}$ & 0.210 & $.368^{* *}$ \\
\hline Body Mass & & & & & & & & \\
\hline & -0.032 & $.269^{\star}$ & 0.031 & 0.201 & 0.135 & 0.225 & 0.080 & $.335^{\star *}$ \\
\hline
\end{tabular}

Note.

** Correlation is significant at the 0.01 level (2-tailed).

* Correlation is significant at the 0.05 level (2-tailed).

\section{Table 5}

Correlations Between the Locomotor and Performance Trials Parameters

\begin{tabular}{|c|c|c|c|c|c|c|}
\hline & & & Yo-Yo & & & Long \\
\hline & Weight & Height & IRTL1 & $30 \mathrm{~m}$ & FMS & Jump \\
\hline Total Distance & 0.065 & 0.012 & 0.002 & -0.163 & -0.195 & 0.210 \\
\hline Velocity Band 4 & $.379^{* *}$ & $.242^{*}$ & 0.221 & $-.476^{* *}$ & 0.010 & $.566^{* *}$ \\
\hline ADI & & & & & & \\
\hline Velocity Band 4 & 0.143 & 0.023 & 0.123 & $-.374^{* *}$ & $-.245^{*}$ & $.305^{*}$ \\
\hline AEC & & & & & & \\
\hline Velocity Band 5 & $.289^{*}$ & 0.207 & 0.224 & $-.456^{* *}$ & 0.000 & $.552^{\star *}$ \\
\hline ADI & & & & & & \\
\hline Velocity Band 5 & 0.209 & 0.094 & 0.102 & $-.439^{* *}$ & -0.201 & $.397^{* *}$ \\
\hline AEC & & & & & & \\
\hline Velocity Band 6 & $.265^{*}$ & 0.202 & 0.043 & $-.467^{\star *}$ & -0.159 & $.415^{* *}$ \\
\hline ADI & & & & & & \\
\hline
\end{tabular}

All authors have read and approved this version of the manuscript. This article was last modified on Month 12, 2020. 
Velocity Band 6

0.160

0.163

AEC

Max. Velocity

$$
.339^{* *}
$$

$.296^{*}$

$0, .198$

$-.411^{\star *}$

$-0.205$

$.360^{* *}$

Note.

** Correlation is significant at the 0.01 level (2-tailed).

* Correlation is significant at the 0.05 level (2-tailed).

\section{Table 6}

Correlations Between Locomotor and Mechanical Parameters

\section{Correlations}

\begin{tabular}{|c|c|c|c|c|c|c|c|}
\hline & \multicolumn{3}{|l|}{ Total } & \multicolumn{4}{|c|}{ Jump } \\
\hline & Player & High & High & Left, & Right, & High & Explosive \\
\hline & Load & Acceleration & Deceleration & High & High & Band & Effort \\
\hline Total Distance & $.881^{* *}$ & $.392^{* *}$ & $.637^{* *}$ & $.485^{* *}$ & $.334^{* *}$ & 0.057 & $.436^{* *}$ \\
\hline $\begin{array}{l}\text { Velocity Band } \\
4 \mathrm{ADI}\end{array}$ & $.369^{* *}$ & 0.174 & $.529^{* *}$ & $.271^{*}$ & $.349^{* *}$ & $.681^{* *}$ & $.292^{*}$ \\
\hline $\begin{array}{l}\text { Velocity Band } \\
4 \text { AEC }\end{array}$ & $.672^{* *}$ & $.334^{* *}$ & $.607^{* *}$ & $.479^{* *}$ & $.304^{*}$ & 0.112 & $.434^{* *}$ \\
\hline $\begin{array}{l}\text { Velocity Band } \\
5 \mathrm{ADI}\end{array}$ & $.282^{*}$ & 0.166 & $.434^{* *}$ & $.259^{*}$ & $.329^{* *}$ & $.631^{* *}$ & $.262^{*}$ \\
\hline $\begin{array}{l}\text { Velocity Band } \\
5 \text { AEC }\end{array}$ & $.503^{* *}$ & $.323^{* *}$ & $.541^{* *}$ & $.412^{* *+}$ & $.382^{* *}$ & $.301^{*}$ & $.415^{* *}$ \\
\hline $\begin{array}{l}\text { Velocity Band } \\
6 \text { ADI }\end{array}$ & 0.222 & 0.211 & $.313^{* *}$ & $.251^{*}$ & $.428^{* *}$ & $.436^{* *}$ & $.304^{*}$ \\
\hline $\begin{array}{l}\text { Velocity Band } \\
6 \text { AEC }\end{array}$ & -0.130 & -0.163 & 0.092 & -0.053 & -0.198 & 0.103 & -0.147 \\
\hline Max. Velocity & -0.152 & -0.166 & 0.137 & 0.005 & 0.022 & $.297^{*}$ & -0.017 \\
\hline
\end{tabular}

Note.

** Correlation is significant at the 0.01 level (2-tailed).

All authors have read and approved this version of the manuscript. This article was last modified on Month 12, 2020. 
${ }^{*}$ Correlation is significant at the 0.05 level (2-tailed).


\section{Figure 1}

\section{Locomotor Values in Different Age Groups}

All authors have read and approved this version of the manuscript. This article was last modified on Month 12, 2020. 


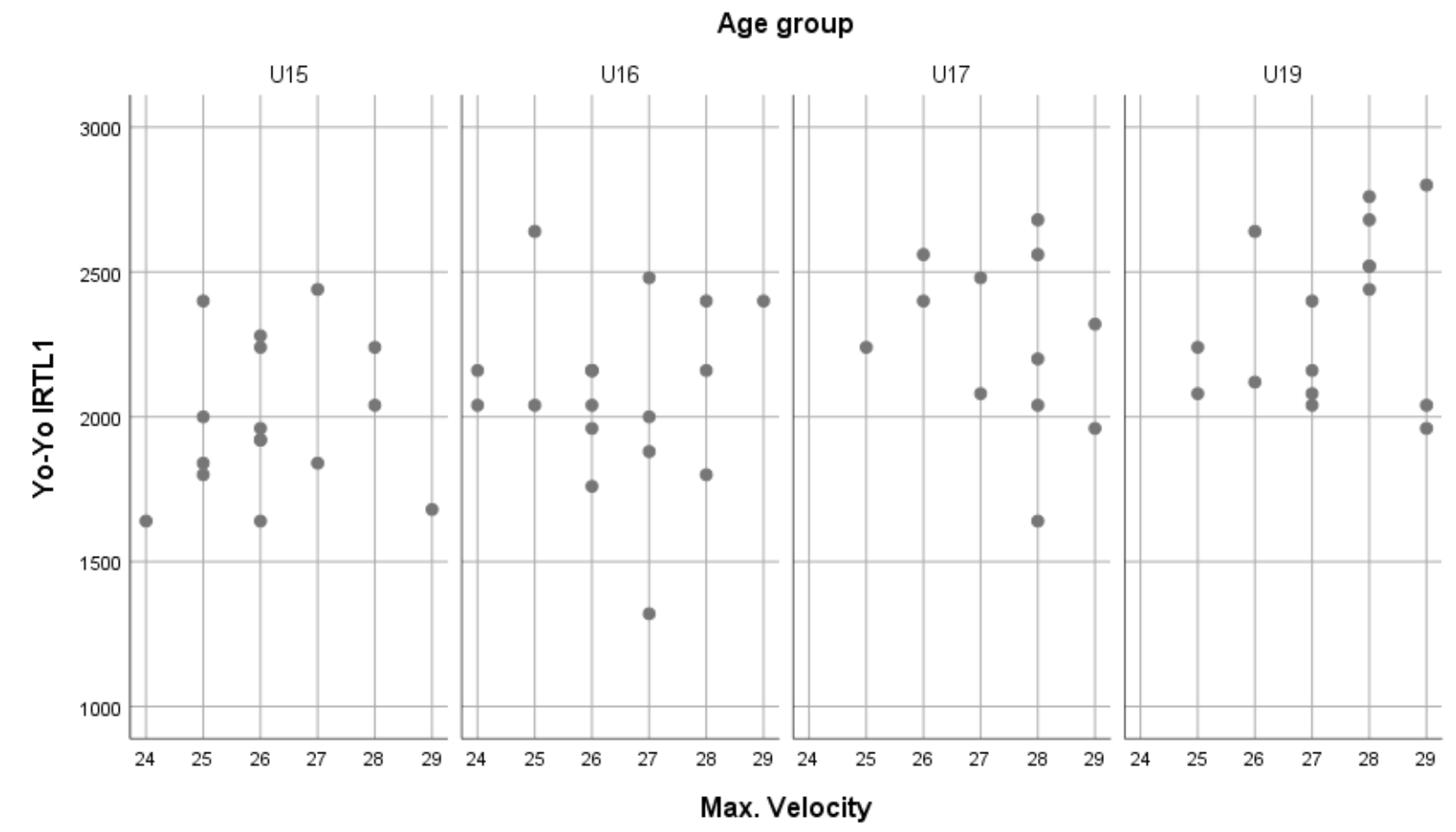

Figure 2

Yo-Yo IRTL1 and Maximum Velocity in Different Age Groups

All authors have read and approved this version of the manuscript. This article was last modified on Month 12, 2020. 


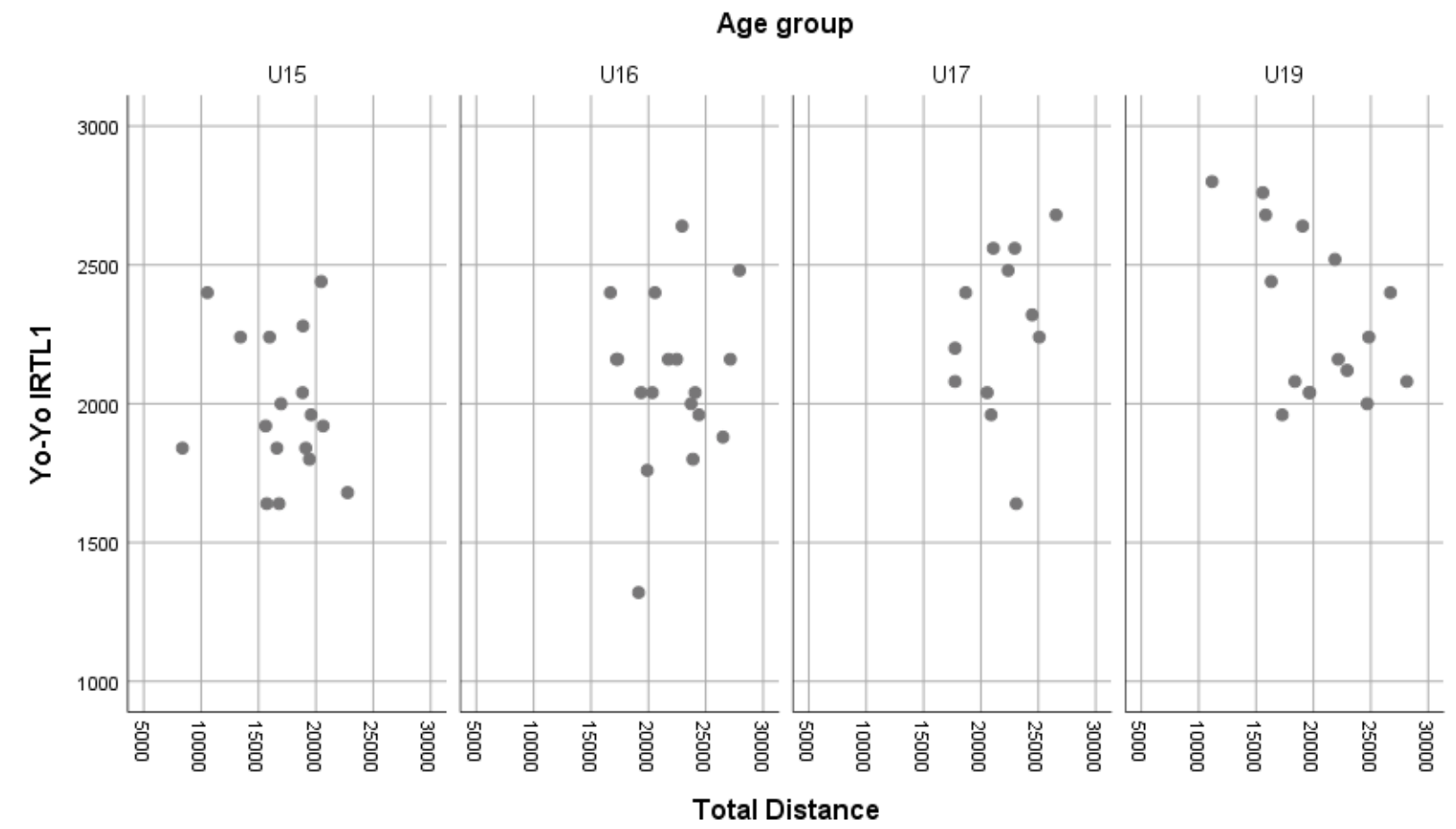

Figure 3 Yo-Yo IRTL1 and Velocity Band 6 ADI in Different Age Groups

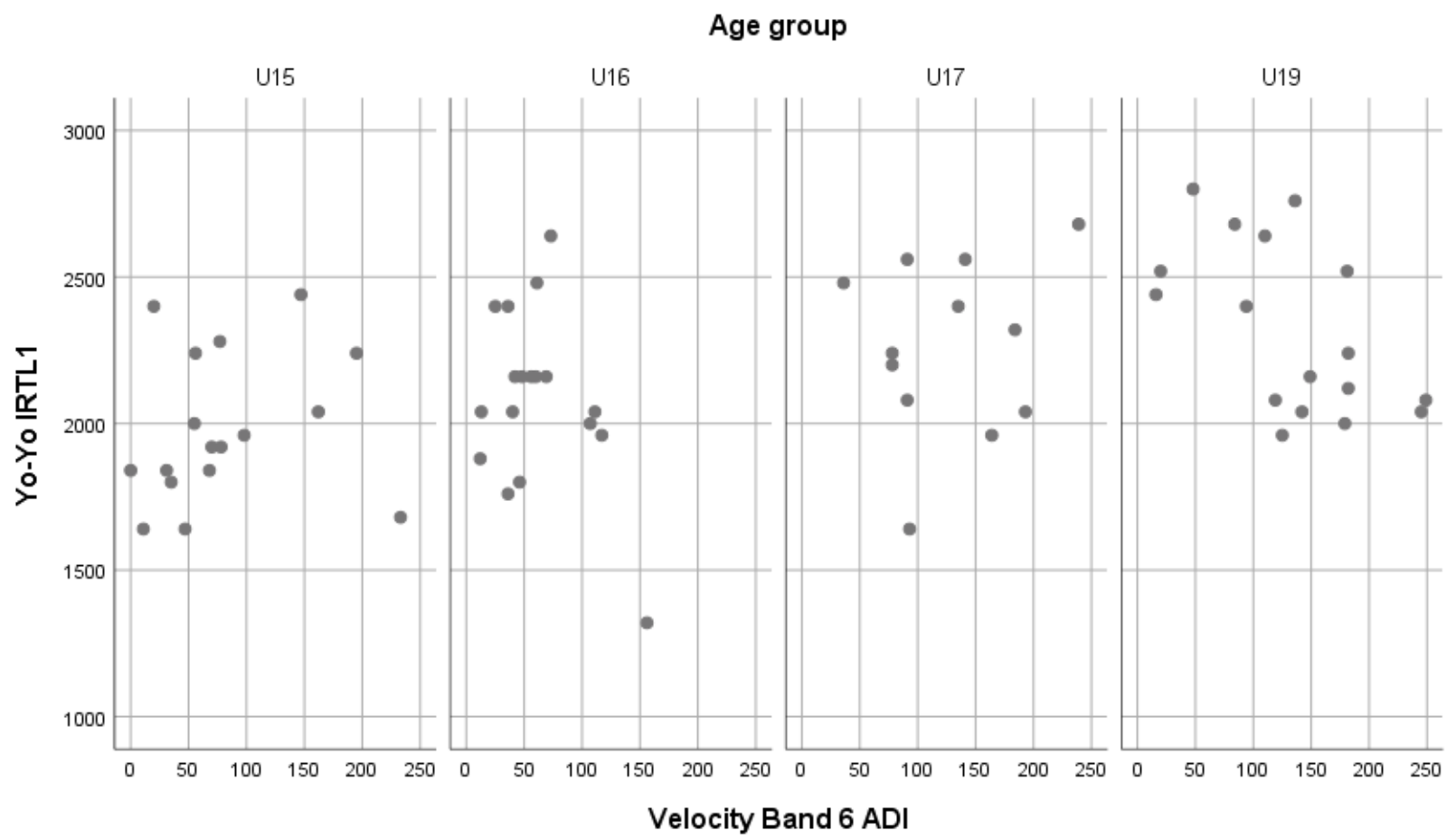




\section{Figure 4}

Yo-Yo IRTL1 and Total Distance in Different Age Groups

All authors have read and approved this version of the manuscript. This article was last modified on Month 12, 2020. 